\title{
Política social, estado e sociedade: reflexões sobre a política de saúde mental
}

\author{
Social, state and political society: Reflections on Mental Health Policy
}

\author{
Sofia Laurentino B. Pereira* \\ Simone de Jesus Guimarães**
}

\begin{abstract}
Resumo:
Este artigo tem como objetivo realizar um debate histórico, teórico e crítico sobre a Saúde Mental enquanto política social, resultante da relação dialética entre Estado e sociedade civil. A metodologia adotada é de caráter qualitativo, consistindo em revisão bibliográfica e reflexiva, por meio da qual se procura avaliar posições de diversos autores sobre o tema. Far-se-á uma discussão da construção histórica da política de Saúde Mental no Brasil, ressaltando a presença de diversos movimentos sociais, como o Movimento dos Trabalhadores em Saúde Mental, o Movimento de Reforma Sanitária, o Movimento de Reforma Psiquiátrica e o Movimento de Luta Antimanicomial. Assim, verifica-se que a sociedade tem grande capacidade de lutar por políticas sociais efetivas, de forma a amenizar as consequências destrutivas do capitalismo. Conclui-se que, apesar da política social não ser capaz de superar a ordem social vigente, ela inclui mudanças significativas no reconhecimento e garantia de direitos à população destituída da riqueza e poder na sociedade.
\end{abstract}

Palavras chaves: Política social. Saúde mental. Estado e sociedade. Reforma sanitária. Reforma psiquiátrica.

\begin{abstract}
:
This article intends to develop a historical, theoretical and critical debate about mental health, as a social policy, resulting from the dialectical relationship between state and civil society. The adopted methodology is qualitative, consisting on a bibliographical and reflexive review, through which it aims to evaluate positions of various authors on the subject. A discussion of the historical development of the Mental Health policy in Brazil was made, emphasizing the presence of various social movements, such as the Workers in Mental Health Movement, the Sanitary Reform Movement, the Psychiatric Reform Movement and the Anti-Asylum Movement. Therefore, it is verified that society has great ability to fight for effective social policies, in order to mitigate the destructive effects of capitalism. It is concluded that, although social policy is incapable of overcoming the social order, it includes significant changes to the recognition and assurance of rights to the people deprived of wealth and power in society.
\end{abstract}

\footnotetext{
* Universidade Federal do Piauí. Mestranda em políticas públicas pela UFPI. Especialista em projetos sociais. Assistente social. E-mail: sofialaurentinobackup@gmail.com

** Universidade Federal do Piauí. Doutora em Serviço Social. Professora do Programa e Pós Graduação em Políticas Públicas da Universidade Federal do Piauí e do Departamento de Serviço Social da mesma instituição. E-mail: simone.guimaraes@uol.com.br
} 
Key words: Social policy. Mental health. State and society. Health reform. Psychiatric reform.

\section{Introdução}

O presente artigo tem o objetivo de realizar um debate histórico, teórico e crítico sobre a Saúde Mental enquanto uma política social, resultante da relação contraditória e dialética entre Estado e sociedade civil. Assim, tem-se a relevância do tema deste trabalho ao pretender proceder a uma análise que possa contribuir para a reflexão e o aprofundamento da Política de Saúde Mental, entendida como inserida na Política de Saúde, no contexto brasileiro atual.

Para tal, o trabalho irá abordar as transformações societárias e suas relações com a formação e o atual desenvolvimento do capitalismo e seu impacto no Estado e especificamente na Política de Saúde Mental, na realidade do Brasil, trazendo diferentes abordagens teóricas e políticas frente às lutas, conquistas e aos retrocessos no campo dos direitos, da democracia, da igualdade e da liberdade.

O artigo está dividido em dois momentos: inicialmente a discussão volta-se às distintas perspectivas de Estado e sociedade, para se chegar a uma concepção de política social; no momento seguinte, será abordada a saúde mental, enquanto uma política social, portanto, inserida em um contexto histórico, político, social, econômico e cultural.

A metodologia adotada para a realização das análises, aqui apontadas, é de caráter qualitativo, consistindo em revisão bibliográfica e reflexiva sobre o tema, por meio do qual se procurou avaliar posições de diversos autores, seja com opiniões distintas, seja com convergentes.

Para a discussão inicial sobre a relação entre Estado e sociedade civil, serão utilizadas as ideias de Mészàros (2011) e Buci-Gluckmann (1980), que faz uma leitura de Gramsci. Em seguida, serão utilizadas as concepções teóricas de Pereira (2009), Faleiros (2000), Behring (2009) e Montaño e Duriguetto (2011) no que diz respeito a seus posicionamentos sobre política social, enquanto resultante da relação contraditória entre Estado e sociedade, os quais se inserem em dados contextos dominados pelo modo de produção capitalista em determinada sociedade. No segundo momento do trabalho, o debate se voltará à saúde 
mental, em que vários autores se posicionam acerca de como esse tema se torna uma Política Social, exigindo um posicionamento oficial do Estado. Rosa (2008) e Vasconcelos (2010) são autores mais enfocados em tal discussão, reforçando a importância dos Movimentos de Reforma Sanitária e Psiquiátrica para dar visibilidade pública à saúde e à saúde mental.

A partir deste debate, reforça-se a visão da política social como um processo, reveladora da interação de um conjunto de determinações históricas, econômicas, políticas e culturais, refletindo a contraditória relação entre Estado e sociedade civil, no âmbito dos conflitos e lutas de classes que envolvem o processo de produção e reprodução do capitalismo.

\section{Estado, Sociedade e Política Social}

Sabe-se que não é possível falar de política social sem compreendê-la enquanto resultante da relação entre Estado e sociedade. Portanto, inicialmente será feita uma discussão sobre essas duas instâncias, ponto de convergência entre diversos teóricos.

Mészàros (2011), de forte tradição marxista, concebe o Estado enquanto funcional ao capital, ou seja, para ele o fundamento do Estado moderno é indissociável da realização dos objetivos materiais do capitalismo. A sobrevivência do sistema do capital, que sempre se volta a sua expansão, exige uma estrutura de comando político cuja função reguladora deve estar condizente com a reprodução econômica direta. Portanto, existe uma relação dialética e de reciprocidade entre capital e Estado. “A formação do Estado moderno é uma exigência absoluta para assegurar e proteger permanentemente a produtividade do sistema" (MÉSZÀROS, 2011, p. 106).

Dessa forma, segundo esse autor, o Estado moderno cumpre a função de remediador das contradições da sociedade, mas nunca ameaçando a reprodução do sistema capitalista. “O Estado se afirma como pré-requisito indispensável para o funcionamento permanente do sistema do capital" (MÉSZÀROS, 2011, p. 108-109). Assim, os benefícios e as políticas sociais, nessa concepção, estão sempre orientados a facilitar a acumulação e a expansão do capital.

lanni (apud PEREIRA, 2009) afirma que não se pode conceber o Estado enquanto um instrumento exclusivo da classe dominante, mas sim como uma instituição constituída e 
dividida por interesses diversos, tendo como principal tarefa administrar esses interesses, mas sem neutralidade.

A concepção de Estado utilizada neste artigo corrobora com a de lanni, baseando-se também na proposta de Estado ampliado de Gramsci, que comporta elementos vinculados à sociedade civil, envolvendo, portanto, sociedade política e civil. De acordo com BuciGluckmann (1980), que faz uma leitura de Gramsci, a sociedade civil envolve uma dupla rede, implicando as condições de vida material, vinculado ao sistema privado de produção e aos aparelhos ideológicos-culturais da hegemonia, que ele chama de aparelho educador do Estado. Sobre essa dupla rede se estende o poder político.

\begin{abstract}
A originalidade do pensamento de Gramsci está na ampliação marxista do conceito de Estado (Estado ampliado), no qual inclui a sociedade. Isso difere da concepção restrita de Estado, de Marx, para quem o Estado é um instrumento de dominação da classe dominante e a Sociedade civil faz parte do terreno estrutural ou da "base material" (PEREIRA, 2009, p. 159).
\end{abstract}

Dessa forma, para Gramsci, o Estado não pode ser concebido apenas como um instrumento nas mãos de uma classe, mas deve ser compreendido enquanto atravessado por uma correlação de forças. Assim como a sociedade civil deve ser entendida enquanto atravessada, tanto econômica quanto ideologicamente, pela luta de classes. Portanto, a ideia de Estado compreende todo um conjunto de atividades teóricas e práticas, com o qual a classe dirigente justifica e mantém não somente a sua dominação, mas, também, consegue obter o consenso ativo dos governados. Desse modo, nesta concepção, não há distinção orgânica entre sociedade civil e Estado, então, ambos serão concebidos como em constante relação (BUCl-CLUCKMANN, 1980).

Pereira (2009) tem um posicionamento semelhante no que diz respeito à relação Estado e sociedade, afirmando que só se pode compreender o Estado pelas suas interdependências com a sociedade, pois é por meio dessa relação que ele abrange todas as dimensões da vida social. Apesar de o Estado ser dotado de poder de coerção e estar, predominantemente, a serviço das classes dominantes, como afirma Mészàros (2011), ele também pode realizar ações protetoras, visando às classes subalternas, em especial, quando essas classes o estejam pressionando para tanto e seja do interesse de sua legitimação. Faleiros (2000) reforça essa ideia, afirmando que o Estado não é um 
instrumento ilimitado de acumulação de capital, mas intervém obrigado pela correlação de forças sociais.

Portanto, o Estado é visto enquanto contraditório, pois atende às necessidades de duas classes contrapostas, incorporando interesses de uma classe ou outra como forma de se legitimar. "É nesta relação com todas as classes que o Estado assume o caráter de poder público e exerce o controle político e ideológico sobre elas" (PEREIRA, 2009, p.147). Tal caráter público pode ser comprometido quando o Estado exacerba em seu poder, virando "as costas" para a sociedade ou para parte dela, tornando-se ditatorial, ficando sujeito a perder o apoio e a confiança que necessita para se perpetuar.

A partir desses conceitos, a política social é, aqui, compreendida como produto da relação dialeticamente contraditória entre Estado e sociedade, e capital e trabalho. Referese a uma política de ação, que visa, mediante esforço organizado e pactuado, atender às necessidades sociais e cuja resolução ultrapassa a iniciativa privada, individual e espontânea, requerendo, portanto, uma deliberada decisão coletiva, regida por princípios de justiça social que devem ser amparados por leis impessoais e objetivas, garantidoras de direitos (PEREIRA, 2009). Nessa mesma direção coloca-se Faleiros (2000, p. 79), ao enfatizar que:

\footnotetext{
O Estado e suas políticas situam-se num marco histórico-estrutural, e não é dentro de uma lógica formal abstrata que se pode compreender suas funções, mas na correlação de forças e lutas sociais e políticas que articulam os movimentos da sociedade com setores do legislativo e do executivo, formando blocos de pressão e negociação onde os interesses dominados podem se manifestar a obter algumas conquistas.
}

Nesse sentido, Manning (apud PEREIRA, 2009) reafirma que a política social está intrinsecamente relacionada ao Estado, aos governos, à política e aos movimentos sociais. Envolvendo, assim, o exercício do poder praticado por indivíduos, grupos, profissionais, empresários, trabalhadores, dentre outros segmentos sociais que tentam influir na sua constituição e direção.

As políticas sociais, portanto, estão relacionadas a conflitos de interesses e suas ações resultam de decisões que visam administrar esses conflitos. E é justamente por meio das políticas sociais que os direitos sociais se concretizam e as necessidades humanas são atendidas na perspectiva da cidadania ampliada (PEREIRA, 2009). 
Ao considerarmos esse entendimento de política social, estamos indo contra ao que Faleiros (2000) chama de concepção instrumentalista e maniqueísta dessa política, de forma a não levar em consideração a realidade da exploração capitalista e da correlação de forças presente em dadas conjunturas sociais. Segundo esse autor, a política social só pode ser entendida dentro do contexto da estrutura capitalista e no movimento histórico das transformações sociais dessas estruturas. Desse modo, não podemos vê-la apenas como funcional ao sistema capitalista, mas sim levar em conta sua face contraditória, que pode incluir ou excluir conforme o poder de negociação ou pressão dos movimentos das classes sociais.

Behring (2009) também tem esse posicionamento e reforça a ideia de que a política social deve ser vista como resultado das contradições estruturais, engendradas pela luta de classes e delimitadas pelos processos de valorização do capital. Portanto, a política social deve ser analisada dentro do movimento histórico e social da sociedade burguesa e capitalista, levando em conta, também, as manifestações das particularidades dos Estados nacionais. A autora enfatiza que:

As políticas sociais são concessões/conquistas mais ou menos elásticas, a depender da correlação de forças na luta política entre os interesses das classes sociais e seus elementos envolvidos na questão. No período de expansão, a margem de negociação se amplia; na recessão, ela se restringe (BEHRING, 2009, p. 315-316).

Assim, as transformações ocorridas dentro do capitalismo refletem nas políticas sociais e nas formas de regulação do Estado perante a sociedade. Percebe-se isso com o projeto neoliberal, que se apresenta como a atual estratégia hegemônica de reestruturação geral do capital, como resposta à crise vivenciada a partir de 1970 . Esse projeto tem como principal característica a redução da intervenção do Estado na sociedade, diminuindo gastos públicos e incentivando a privatização e a refilantropização do social. Nesse contexto, tem-se uma redução das políticas sociais, principalmente as de caráter universal, e uma expansão de políticas focalizadas e seletivas, voltadas, sobretudo, às situações emergenciais de extrema pobreza.

Diante desse contexto, Behring (2009) aponta tendências que operam no campo das políticas sociais na atualidade: a desresponsabilização do Estado e do setor público perante 
uma política social de redução da pobreza articulada a outras políticas sociais; redução de fundos e investimentos do Estado e setor público em políticas sociais universais, voltandose para o incentivo à privatização e mercantilização dos serviços; políticas voltadas à pobreza de forma focalizada, emergencial e reduzida à dimensão assistencial.

Montaño e Duriguetto (2011) afirmam que o avanço do neoliberalismo - e suas outras faces, como a globalização, a reestruturação produtiva, a mundialização do capital, dentre outros - tem repercussão direta nas lutas de classes. A redução da proteção social por parte do Estado tem impactos tanto objetivos, como desemprego, precarização e fragmentação do trabalho, quanto subjetivos na ideologia e culto a uma apologia de individualismo e enfraquecimento da consciência de classe dos trabalhadores. Portanto, a luta de classes vai sendo desmobilizada, desorganizada e segmentada. Assim se expressam os autores:

O Estado se afasta do papel de "regulador", e a relação entre empregados e empregadores passa a comandar os "acordos" nas empresas. As leis trabalhistas são desmontadas ("flexibilizadas"), passando agora a aprimorar o acordo (entre as partes) sobre a lei - e acordos produzidos numa relação tão desigual que só podem confirmar e ampliar tal desigualdade (MONTANÕ; DURIGUETTO, 2011, p. 201).

Com essa fragmentação e diminuição do poder dos trabalhadores, o capital pode, sem maiores resistências, avançar mais facilmente no seu processo de ofensiva contra o trabalhador, na busca incessante pela expansão dos lucros, diminuindo, cada vez mais, os gastos com políticas sociais de caráter universal, ocorrendo, portanto, o crescimento do poder do grande capital.

Por isso, reforça-se a necessidade de fortalecimento da classe trabalhadora, adotando o posicionamento, da tradição marxista, de que ela é a única e verdadeira classe capaz de promover uma revolução nas estruturas sociais. Portanto, apesar do avanço do capitalismo, os trabalhadores devem ter consciência de sua força perante a relação entre Estado e sociedade. Nesse sentido, a mobilização da sociedade civil, no país, em luta por transformações sociais mais substantivas para a sociedade, é a alternativa capaz de amenizar as consequências destrutivas do sistema capitalista na conjuntura atual. 


\section{Política de Saúde Mental no Brasil}

Segundo Frayze-Pereira (1984), historicamente, a forma de tratamento da "loucura" esteve sempre ligada ao enclausuramento e à exclusão, mesmo quando ainda não havia sua relação como tratamento médico. Com a sociedade moderna, burguesa e capitalista, ocorreu o apogeu da psiquiatria, entretanto, o "louco" ainda continuava circunscrito à segregação social, condensado no formato de tratamento denominado de hospitalocêntrico, ${ }^{1}$ que abarcava a totalidade da vida do ser humano, impedindo o seu convívio social. Nesse contexto, a pessoa com transtorno mental era vista apenas em sua enfermidade, desconsiderada em sua perspectiva social. Rosa (2008) e Vasconcelos (2010) vão corroborar com essa perspectiva, afirmando que, no Brasil, não aconteceu de forma diferenciada.

Nesse país, tradicionalmente, o modelo de tratamento em saúde mental esteve pautado no isolamento, na tutela, na vigilância, na repressão e na disciplina, sendo que o espaço onde se desenvolviam essas ações era o manicômio, onde o sujeito era visto como dotado de uma periculosidade social (ROSA, 2008).

Essa perspectiva da institucionalização e segregação, como forma de lidar com a pessoa com transtorno mental, predominou durante muito tempo, até a emergência do Movimento de Reforma Psiquiátrica, em 1970, em conjunto com o processo de luta pela redemocratização brasileira (VASCONCELOS, 2010). É nesse contexto histórico, após vinte anos de ditadura militar, que o país inicia um movimento de redemocratização dos espaços de decisão política, de ascensão dos movimentos sociais vinculados à luta da classe trabalhadora e ao ressurgimento da luta dos profissionais da saúde e usuários em busca da construção de um Sistema de Saúde Único universal, gratuito, igualitário e de qualidade.

A partir desse momento, passa-se a exigir o estatuto de cidadania à pessoa com transtorno mental, colocando-se em xeque o antigo modelo manicomial e se exigindo a criação de serviços substitutivos e comunitários a essa pessoa. Nesse quadro de análise, a pessoa com transtorno mental seria restituída em sua integralidade e o foco da atenção dos

\footnotetext{
${ }^{1} \mathrm{O}$ chamado modelo hospitalocêntrico representava o isolamento da pessoa com transtorno mental em hospitais psiquiátricos, onde era retirado do convívio comunitário e familiar e visto apenas na perspectiva da doença, desvalorizado em suas outras perspectivas humanas. Esse modelo sofreu denúncias de violação dos direitos das pessoas que ali estavam internadas.
} 
profissionais de saúde mental se ampliaria e estaria voltado para além dos sintomas e dos medicamentos, ou seja, para outras dimensões sociais da vida desses sujeitos sociais.

Nesse período, com a mobilização e pressão dos Movimentos de Reforma Sanitária e Reforma Psiquiátrica, além da influência favorável do contexto internacional, ${ }^{2}$ a questão da saúde mental passa a ganhar visibilidade pública; fato, esse, que a levou a sua concretização como uma política pública e social, com ações legais partindo do Estado, voltadas às pessoas com transtorno mental, agora consideradas sujeitos de direitos.

Lima (2004) afirma que o Movimento de Reforma Sanitária foi de grande importância à saúde e à saúde mental, pois esse movimento lutava por um novo modo de conduzir a saúde pública no Brasil, ao propor um novo projeto de assistência à saúde médica e hospitalar, compromissada com os interesses dos pacientes, tendo o Estado um papel primordial nesse processo, assegurando que a saúde em geral e a saúde mental fosse um direito social de todos e um dever estatal. Nesse contexto, o Estado deveria assegurar serviços de qualidade, tratando os portadores de transtorno mental como sujeitos de direitos.

No cerne do Movimento de Reforma Sanitária, surge o Movimento de Reforma Psiquiátrica, em 1978, adquirindo uma identidade singular em relação ao primeiro, já que sua atuação volta-se mais à pessoa com transtorno mental, batalhando pela desinstitucionalização da assistência psiquiátrica por meio da criação de serviços abertos e comunitários, que atendessem às necessidades sociais do indivíduo com transtorno mental que, historicamente, convivia e ainda convive com a exclusão e a segregação social (VASCONCELOS, 2010).

Ao analisar os movimentos ocorridos na década, Vasconcelos (2010) afirma que é no ano de 1978 que ocorre a emergência dos principais movimentos sociais no Brasil. Esse é o contexto em que se inicia, de modo mais efetivo e amplo, o movimento social pelos direitos dos pacientes psiquiátricos no país. Nesse quadro de lutas, emerge, no mesmo período, o Movimento dos Trabalhadores em Saúde Mental, que se destaca por protagonizar denúncias com relação à violência dos manicômios e à mercantilização da loucura,

\footnotetext{
${ }^{2}$ A partir da segunda metade do século XX, impulsionada, sobretudo, por Franco Basaglia, psiquiatra italiano, iniciou-se uma radical crítica e transformação do saber, do tratamento e das instituições psiquiátricas. Esse é um movimento que se inicia na Itália, mas tem repercussões em todo o mundo e muito particularmente no Brasil (AMARANTE, 1998).
} 
colocando-se na perspectiva de construir, coletivamente, uma crítica sobre essa realidade e apontando novas propostas à assistência às pessoas com transtornos mentais, até então baseadas no asilamento em hospitais psiquiátricos.

Em 1986, ocorreu a oitava Conferência Nacional de Saúde no Brasil, considerada um marco na discussão da saúde no país. Essa Conferência buscava a concretização dos ideais propostos pelo Movimento de Reforma Sanitária, culminando suas principais ideias na promulgação da Constituição Federal de 1988. No Rio de Janeiro, em 1987, ano seguinte após a realização dessa Conferência de Saúde, acontece a I Conferência Nacional de Saúde Mental no país, a qual propõe a reorganização dos serviços assistenciais na área, reforçando a ideia de substituição do modelo hospitalocêntrico pelos serviços alternativos. Nesse período, o Movimento de Trabalhadores de Saúde Mental se transforma em Movimento Nacional de Luta Antimanicomial (ROSA, 2008).

Após a oitava Conferência Nacional de Saúde, o conceito de saúde plena passa, cada vez mais, a ser defendido, representando, em seu significado, que saúde vai além da sua relação com a doença, para se constituir como resultado das formas de organização social da produção que podem gerar grandes desigualdades, repercutindo nos diversos níveis de vida da população. Esse conceito, discutido tanto nacionalmente como mundialmente, via a saúde como resultante e condicionante de um conjunto de fatores, dentre eles as condições de alimentação, habitação, educação, renda, trabalho. Assim, foi sendo reforçada, sobretudo, nesse período, a partir da mudança desse conceito, uma transformação na luta pela saúde no Brasil, inserida em uma batalha em escala global (ESCOREL, 1995).

A Constituição Federal de 1988 pretendia a construção de uma ordem institucional democrática, que supunha um reordenamento das políticas sociais de forma que respondessem às demandas da sociedade por maior inclusão social e equidade. Projetada para o sistema de políticas sociais como um todo, tal demanda por inclusão e redução das desigualdades adquiriu as concretas conotações de afirmação dos direitos sociais como parte da cidadania (FLEURY, 2009).

A Carta Magna representou uma profunda transformação no padrão de proteção social brasileiro, positivando, em lei, as pressões que já se faziam há mais de uma década no país. Inaugura-se um novo modelo de seguridade social e de política social, 
caracterizadas pela universalidade de cobertura, reconhecimento dos direitos sociais, afirmação do dever do Estado, subordinação das práticas privadas à regulação em função da relevância pública das ações e serviços nas áreas, além de uma perspectiva de gestão compartilhada entre governo e sociedade civil (FLEURY, 2009).

Após a promulgação da Constituição de 1988, Vasconcelos (2010) aponta o lançamento do Projeto de Lei Paulo Delgado, em 1989, como uma das primeiras iniciativas oficiais do Movimento de Luta Antimanicomial. Tal Projeto de Lei defendia a progressiva extinção dos hospitais psiquiátricos no Brasil, delegando ao Estado a responsabilidade pela criação de serviços alternativos e extra-hospitalares. Rosa (2008) afirma que esse Projeto de Lei gerou grandes debates na mídia nacional, de forma que tal lei só foi aprovada mais de dez anos depois, no ano de 2001.

Em 1990, ocorre a aprovação das leis federais 8.080, instituindo o Sistema Único de Saúde (SUS), e 8.142, criando a Lei Orgânica da Saúde (LOS). Ambas dispondo sobre a promoção a proteção e a recuperação da saúde da população. Tais leis tiveram grande relevância para a melhoria do Sistema de Saúde, inclusive na área de saúde mental, na medida em que estimularam a articulação das diferentes políticas de saúde, tendo em vista um olhar mais coletivo sobre a área no enfrentamento das necessidades sociais básicas que a sociedade exige.

Com a promulgação da Constituição Federal de 1988 e a instituição das leis 8080 e 8142, a saúde se estrutura enquanto um direito, não apenas como reconhecimento da sobrevivência individual e coletiva, mas como direito ao bem-estar completo e complexo, articulado às condições de vida em suas dimensões biológica, cultural, social, psicológica e ambiental, conforme preconiza a definição da Organização Mundial da Saúde. Dessa forma, a saúde passa a ser considerada na sua complexidade, colocando-se como um bem econômico não restrito ao mercado, mas como forma de vida da sociedade; um direito que se afirma como política pública, com características de acesso universal, qualidade e hierarquização (BRASIL, 2006).

Entretanto, tais leis, apesar de sua enorme importância, tiveram pouco impacto na melhoria das reais condições de saúde da população, pois sua operacionalização ocorreu muito lentamente (BRAVO, 2009). Assim, o que se constata é que mesmo com a promulgação da Constituição de 1988 e a implantação do SUS, as mudanças na realidade 
ocorrem de forma vagarosa, mas ainda contínua dos serviços de assistência psiquiátrica no Brasil (ROSA, 2008).

Bravo (2009) afirma que na década de 1990, ainda no período de implementação das experiências de participação e de viabilização das políticas sociais, o país se vê diante de uma ofensiva ideológica do neoliberalismo, ocorrendo, então, um redirecionamento do papel estatal, com a justificativa de que o Estado não poderia mais atender, como antes, à reprodução da força de trabalho devido à crise econômica que se encontrava.

Dessa forma, na década de 1990, o Brasil passa por uma dualidade: de um lado, encontra-se a aprovação da nova Constituição, que trouxe avanços na questão dos direitos sociais, na aprovação do Sistema Único de Saúde e na criação de inúmeras outras leis e portarias a favor da universalidade e equidade; de outro lado, presencia-se a ofensiva neoliberal, que é a favor da privatização e da mercantilização dos serviços, provocando uma diminuição dos direitos recém-conquistados, por meio de políticas cada vez mais compensatórias.

Portanto, com o avanço do neoliberalismo, no país, a proposta da Política de Saúde, construída na década de 1980, que tinha como base o Movimento de Reforma Sanitária, vai sendo, aos poucos, desconstruída. A saúde passa a vincular-se ao mercado, em parceria com a sociedade civil, que passa a ser responsabilizada a assumir os custos da crise do capital (BRAVO, 2009).

Entretanto, mesmo em um contexto de políticas governamentais influenciadas pelas propostas neoliberais, o campo de saúde, como tem se demarcado, é um campo de lutas e embates. Nessa perspectiva, observa-se a concretização de avanços no sentido de desmonte do modelo hospitalocêntrico, após três décadas do início do Movimento de Reforma Psiquiátrica (VASCONCELOS, 2010).

Nesse sentido, mesmo que, simultaneamente, a ofensiva neoliberal demarque posições quanto à diminuição do papel do Estado na formulação de políticas públicas universais, ainda, assim, ocorre a expansão dos serviços psiquiátricos substitutivos, principalmente, no que se refere à instalação de centros e núcleos de atenção psicossocial, em paralelo ao processo de fechamento de leitos e instituições hospitalares (VASCONCELOS, 2010). É, também, a partir de 1990, que o Ministério da Saúde edita várias Portarias, tanto para modificar a sistemática de remuneração das internações psiquiátricas 
- visando reduzir o tempo de internação - como para criar outros procedimentos na área da saúde mental, relacionados, por exemplo, às internações e consultas ambulatoriais. Esse conjunto de ações estatais dará início à atual Política Nacional de Saúde Mental.

Em 1990, ocorre, em nível internacional, a realização da Conferência de Caracas, que cria um consenso mundial em torno da nova plataforma de Reforma Psiquiátrica, a ser conduzida pelos governos assinantes. Essa Conferência cria um documento que marca as reformas na atenção à saúde mental nas Américas, reunindo organizações, associações, autoridades de saúde, profissionais de saúde mental, legisladores e juristas em busca de uma reestruturação da assistência psiquiátrica dentro dos sistemas locais de saúde, propondo a extinção e a substituição gradativa dos serviços manicomiais. Após essa ampla conferência e sob sua influência, haverá uma discussão sobre a implantação das estratégias da reforma psiquiátrica no país, culminando na II Conferência Nacional de Saúde Mental, em 1992. Foi nesse período que foram implementadas as primeiras experiências municipais de rede de cuidados em saúde mental a partir do novo modelo proposto pela reforma (VASCONCELOS, 2010).

Vasconcelos (2010) aponta o Núcleo de Atenção Psicossocial (NAPS) criado em Santos, no Estado de São Paulo, como o principal exemplo do início da implantação de serviços substitutivos nos municípios. Esse NAPS foi considerado uma experiência inicial dos Centros de Atenção Psicossocial (CAPS), por ser um serviço comunitário de portas abertas que funcionava durante a semana.

Balizadas pelo compromisso firmado pelo Brasil na assinatura da Declaração de Caracas e pela realização da II Conferência Nacional de Saúde Mental, entram em vigor novas portarias ministeriais com o fim de regulamentar os serviços de atenção diária, que passam a ser fundados nas experiências dos (primeiros) Centros de Atenção Diária (CAD), nos Centros de Atividades Integradas em Saúde Mental (CAIS), nos hospitais-dia, nas oficinas terapêuticas, nos clubes de convivência, em moradias assistidas, nos Núcleos de Atenção Psicossocial (NAPS), nos Centros de Atenção Psicossocial (CAPS), dentre outros (BISNETO, 2009).

Esse conjunto de leis e portarias é fundamental para o processo de intensificação da reforma psiquiátrica no país. Como parte dessa realidade é promulgada a Lei federal de 10.216, de 06 de abril de 2001, que veio proteger os direitos das pessoas portadoras de 
transtornos mentais e redirecionar o modelo assistencial em saúde mental, determinando que os pacientes, há longo tempo internados em hospital psiquiátrico, com uma situação de grave dependência institucional, sejam objetos de política específica. O objetivo principal dessa lei é a inclusão social desses pacientes e a ampliação do atendimento extrahospitalar (BISNETO, 2009).

Veloso (2009), ao analisar a Lei 10.216, mostra que ela reafirma a responsabilidade do Estado para com o desenvolvimento da política de saúde mental, a assistência e a promoção de ações de saúde às pessoas com transtornos mentais, com participação da sociedade e da família, visando à reinserção social do indivíduo em seu meio.

Em 19 de fevereiro de 2002, mais uma Portaria Ministerial é regulamentada: a de $\mathrm{n}^{\circ}$ 336. Essa portaria regulamenta o funcionamento dos Centros de Atenção Psicossocial (CAPS), definindo que esses devem atuar, também, em rede com outros serviços, tais como o Programa Saúde da Família, os ambulatórios, as Residências Terapêuticas, os Centro de Referência de Assistência Social entre outros. O CAPS é considerado um componente estratégico de uma política destinada a diminuir a lacuna no atendimento a pessoas com transtornos mentais (BRASIL, 2004).

Com base no exposto, conclui-se que a Política de Saúde Mental deve ser entendida em conformidade ao que planteia o Relatório Final da IV Conferência Nacional de Saúde Mental, publicado pelo Ministério da Saúde em 2010. Nesse documento, reafirma-se o caráter efetivamente público dessa política, de responsabilidade dos três níveis de governo, com garantia de dotação orçamentária específica, espaços físicos próprios, condições materiais e técnicas adequadas, para a viabilização do novo modelo assistencial (BRASIL, 2010). Além disso, concebe a saúde mental como integral e universalmente inserida em todas as esferas de saúde, de forma que os usuários tenham participação em todos os níveis de atenção. Essa política deve estar de acordo com os princípios, diretrizes e normas do Sistema Único de Saúde, da Lei Federal no 10.216 de 2001 e da Reforma Psiquiátrica. Esse conjunto de leis e normas, que conformam a Política de Saúde Mental brasileira, deve sempre estar pautado nos princípios da Reforma Psiquiátrica, que propõe implantar, ampliar, consolidar e fortalecer a rede de serviços substitutivos em Saúde Mental, em todo o país, com prioridade para as regiões com vazios assistenciais, garantindo acesso, acolhimento e tratamento de toda a população, em todos os níveis de assistência. 


\section{Considerações finais}

Enfim, foi possível observar que não existe um conceito único a respeito de Estado, sociedade e política social, apontando-se, aqui, algumas concepções teóricas divergentes ou não. Buscou-se, no entanto, reforçar a ideia de política social como um processo, reveladora da interação de um conjunto de determinações históricas, econômicas, políticas e culturais, fruto da contraditória e complexa relação entre Estado e sociedade civil, dentro de um contexto de expansão e dominação do sistema capitalista.

Observou-se que, no processo de construção das políticas sociais de Saúde e Saúde Mental, no Brasil, vários movimentos sociais fizeram-se presentes, reforçando a importância de uma sociedade civil organizada e conscientizada, como forma de lutar por seus direitos. As atuais políticas sociais foram resultado, portanto, de mudanças na relação Estado e sociedade civil no Brasil, que trouxe uma maior intervenção estatal na esfera social, sobretudo, pós-Constituição de 1988 e por meio de um sistema participativo, com controle social sobre as políticas e ações governamentais.

A política de Saúde Mental é concebida dentro da política de Saúde, guiada pelo Sistema Único de Saúde, pela Constituição Federal de 1988 e pelas Leis federais de $\mathrm{n} 08080$ e 8142 de 1990. A partir dessas normativas legais e tendo por base os movimentos da sociedade civil, a Saúde Mental passa a ser considerada, no Brasil, no século XX, uma política pública e social, quando o Estado a coloca como uma preocupação central, uma questão social que precisa de respostas mais sofisticadas por parte do aparelho estatal.

O que se pode assinalar é que, ao longo dos últimos trinta anos, o campo da saúde mental obteve grandes avanços, como a aprovação de uma ampla legislação voltada aos direitos das pessoas com transtorno mental, assim como ampla divulgação de ações e estratégias que essa política pública vem desenvolvendo nos serviços e dispositivos substitutivos ao hospital psiquiátrico em várias regiões dos pais.

Enfim, apesar do avanço do neoliberalismo no Brasil, que veio desmontando os direitos sociais e políticas sociais universais duramente conquistadas, não se pode negar: há um avanço na área da saúde e da saúde mental, tanto comparado como elas eram tratadas anteriormente pelo Estado quanto comparadas a outras áreas. Isso se deve 
principalmente ao fato de que esse é um campo de lutas e embates, em que a sociedade civil mostrou-se ativa, com a presença de diversos movimentos sociais, como o Movimento dos Trabalhadores em Saúde Mental, o Movimento de Reforma Sanitária, o Movimento de Reforma Psiquiátrica e o Movimento de Luta Antimanicomial.

Importa ainda ressaltar que esses movimentos vêm sofrendo ataques, por conta de toda conjuntura de desmobilização dos movimentos sociais, consequente da ofensiva neoliberal e do avanço da globalização do capitalismo. Ao longo dos últimos anos, assim como o movimento geral da luta dos trabalhadores, os movimentos em defesa da saúde mental também vêm apresentando um retrocesso, o que gera uma fragilidade na articulação política e na mobilização social em torno da luta pelo fortalecimento de uma política pública e social de Saúde Mental.

Portanto, apesar do avanço significativo do campo da saúde mental, ainda se fazem necessárias muitas ações e estratégias de mobilização social e política que possam fomentar o processo de fortalecimento dos princípios da Reforma Sanitária e Psiquiátrica no Brasil.

A partir desta discussão, conclui-se que apesar de a política social não ser capaz de superar a atual ordem social, ou provocar revoluções, ela inclui mudanças significativas no reconhecimento e garantia de direitos da população, em especial, àquela vinculada às classes subalternas. E a sociedade civil organizada é a única que tem capacidade de lutar para pôr políticas sociais efetivas, de forma a amenizar as consequências destrutivas do sistema capitalista.

\section{Referências}

AMARANTE, P. Loucos pela vida: a trajetória da reforma psiquiátrica no Brasil. Rio de Janeiro: Fundação Oswaldo Cruz, 1998.

BEHRING, E. R. Política social no contexto da crise capitalista. In: . Serviço social: direitos sociais e competências profissionais. Brasília: CFESS/ABEPSS, 2009. p. 302-321.

BISNETO, J. A. Serviço social e saúde mental: uma análise institucional da prática. 2. ed. São Paulo: Cortez, 2009.

BRASIL. Ministério da Saúde. Secretaria de Atendimento à Saúde. Saúde mental no SUS: Os Centros de Atenção Psicossocial. Brasília: Ministério da Saúde, 2004.

. A construção do SUS: história da Reforma Sanitária e do processo participativo. Brasília: Secretaria de Gestão Estratégica e Participativa, 2006. 
. Conselho Nacional de Saúde. Relatório final da IV Conferência Nacional de Saúde $\overline{M e n t a l}$ - Intersetorial. Brasília: Conselho Nacional de Saúde, 2010.

BRAVO, M. I. Política de saúde no Brasil. In: MOTA, A. E. et al. Serviço social e saúde. 4. ed. São Paulo: Cortez, 2009. p. 88-110.

BUCI-CLUCKMANN, C. Gramsci e o Estado. Rio de Janeiro: Paz e terra, 1980.

ESCOREL, S. Saúde: uma questão nacional. In: TEIXEIRA, S. F. (Org.). Reforma sanitária: em busca de uma teoria. 2. ed. São Paulo: Cortez; Rio de Janeiro: Associação Brasileira de Pós-Graduação em Saúde Coletiva, 1995. p. 181-192.

FALEIROS, V. P. A política social do estado capitalista. 8. ed. São Paulo: Cortez, 2000.

FLEURY, S. Reforma sanitária brasileira: dilemas entre o instituinte e o instituído. Ciência e Saúde Coletiva, Rio de Janeiro, v. 14, n. 3, p. 743-752, 2009.

FRAYZE-PEREIRA, J. A. O que é loucura. 3. ed. São Paulo: Brasilense, 1984.

LIMA, M. J. G. A prática do Assistente Social na área da saúde mental: uma analise centrada na cidadania dos usuários. 2004. Dissertação (Mestrado em Políticas Públicas) UFPI, Teresina.

MÉSZÀROS, I. Para além do capital: rumo a uma teoria da transição. São Paulo: Boitempo, 2011.

MONTAÑO, C.; DURIGUETTO, M. L. Estado, classe e movimento social. 2. ed. São Paulo: Cortez, 2011. (Biblioteca básica de serviço social, v. 5).

PEREIRA, P. Política social: temas e questões. 2. ed. São Paulo: Cortez, 2009.

ROSA, L. C. S. Transtorno mental e o cuidado na família. 2. ed. São Paulo: Cortez, 2008.

VASCONCELOS, E. M. Saúde mental e serviço social: o desafio da subjetividade e da interdisciplinaridade. 5. ed. São Paulo: Cortez, 2010.

VELOSO, L. U. P; CARLOS, K. P. T. A nova política de saúde mental no Estado do Piauí: Mudanças e Perspectivas. In: ROSA, Lúcia C. dos Santos (org.). Cenários de práticas em saúde mental: a atenção psicossocial no Piauí. Teresina: EDUFPI, 2009. p.103-111 